\title{
NOTE ON THE OCCURRENCE OF NEEDLE BLIGHT AND LATE FALL BROWNING IN RED PINE (Pinus resinosa Ait.).
}

\author{
By W. R. Haddow and M. A. Adamson
}

$\mathrm{T}^{\mathrm{H}}$ HE OCCURRENCE of conspicuous injury in red pine plantations on account of fungus or insect attack is sufficiently novel to be worthy of note for this species is comparatively free of disease and pests and is often favoured for reforestation on that account. During the last few years there has been observed at Midhurst, Ontario, and at a few other localities, certain needle affections of trees in young plantations which, though as yet the cause of no mortality, have been sufficiently severe at times to arouse some apprehension. The first of these is a characteristic blight of the foliage of the current season, which is the cause of a more or less severe defoliation. The second is a remarkable late fall browning, also of the current season's needles, which at times has been of such severity in the younger plantations as to suggest their having been run through by fire. Though typically each of these affections is distinct and characteristic with respect to symptoms and development, it is now believed that there exists a common initial causal circumstance in the ovipositing of a gall midge.

To our knowledge, infestation of red pine by gall midges (Cecidomyidae) has not been reported heretofore. Such, however, has been recognized in the case of other species of Pinus. Thus in North America several western pines are hosts for Thecodiplosis piniradiatae (Snow and Mills), ${ }^{1}$ and in the east Pinus rigida is attacked by Cecidomyia pinirigidae (Peck). Felt ${ }^{2}$ has recently described a species from Connecticut causing foliage injury in white and Scots pine, but questions whether it is new to science. In Europe, sev. eral species are known to cause damage to pine, especially in plantations. Chief among these is Thecodiplosis brachyntera (Schwäg), which infests particularly the Scots pine. This insect and its work have recently been studied in Germany by von Tubeuf ${ }^{ \pm 6}$. Similarly, Smolak ${ }^{3}$ gave an account of several epidemics in Czechoslovakia.

\section{REFERENCES}

1. Doane, R. W., et al. Forest insects, 1936.

2. Felt, E. P. New midges on pine and grass. Jour. N.Y. Entomol. Soc. 44:1 7-10 1936 .

3. Smolák, J. Bejlomorlka borová (The codiplosis brachyntera schwäg) na prazskych kosodrevinách. Ochrana Rostlin 12: 5-6. 100-103. 1932.

4. von Tubeuf, C. F. Epidemische Entnadelung Kurtztriebverlust) der Kiefernsprosse durch Cecidomyiose (Brachynterie) Zeitschr. 1. Pflkrank. 42: 2.58-88. 1932.

5. - - - 42: 3.97-121. 1932.

6. - - Ein ungewöhnlicher Fall von ausgedehnter Cecidomyiose in einem Kiefernstangenholze. Zeitschr. f. Pflkrank. 43: 1. 29-31. 1933. 
The needle blight which we describe was first noticed at Midhurst in 1932, and since that time both phases (blight and late fall browning) have occurred there and at other localities in Simcoe county, namely, the Hendrie forest, Orr Lake forest, and near the village of Angus. During the last two seasons plantations in the Durham county forest were affected.

As far as our observations go, only trees in close plantations suffer attack. At the several localities mentioned, the disease did not occur on large native red pines, nor on isolated specimen trees. The plantations affected have ranged in age from five to fifteen years and the incidence of disease has been, on the whole, remarkably uniform therein. Of varying size, such areas have comprised, in the case of fall browning, as much as twelve acres in contiguity. The needle blight phase has commonly involved scattered areas of smaller size. Both types have appeared suddenly in new localities, but the fall browning has been recurrent for two or three years on the same area, a circumstance which has not been evident in the case of blight. The incidence of each has fluctuated from year to year but, on the whole, blight has been most prevalent during the wetter summers. In the notably hot and dry season of 1936 practically no blight occurred but fall browning was unusually prevalent and severe. Blight has appeared as early as late July but more commonly in August. Fall browning, on the other hand, has not been detected before the middle of September and it attains its maximum intensity late in October.

A plantation suffering from "needle blight" presents a characteristic appearance. As much as a half of the foliage of the current season (which alone is susceptible) may be killed. Both needles of the short shoot are involved though, rarely, one may remain green temporarily. The needles are sharply bent or hooked within the sheath (the whole forming a crook) in which habit they hang until abscissed and cast. The normal needle fall, coming from the inner (proximal) position on the boughs, passes in the main directly to the ground without much interference. Needles falling from the distal shoots, however, are intercepted and tend to accumulate on the green foliage. This accumulation is aggravated in the present instance on account of the crooking of the needle pairs for such needles are easily caught and are retained very persistently. Thus a blighted plantation exhibits a remarkably "untidy" appearance-the terminal shoots spike-like through loss of foliage, with awry needles attached, and the boughs littered with hooked fascicles. The burden of needles on the ground is, of course, unusually heavy. In the early spring, affected plantations look particularly bad on account of the paucity of foliage but with the spreading of the new growth the damage is remarkably well masked. 

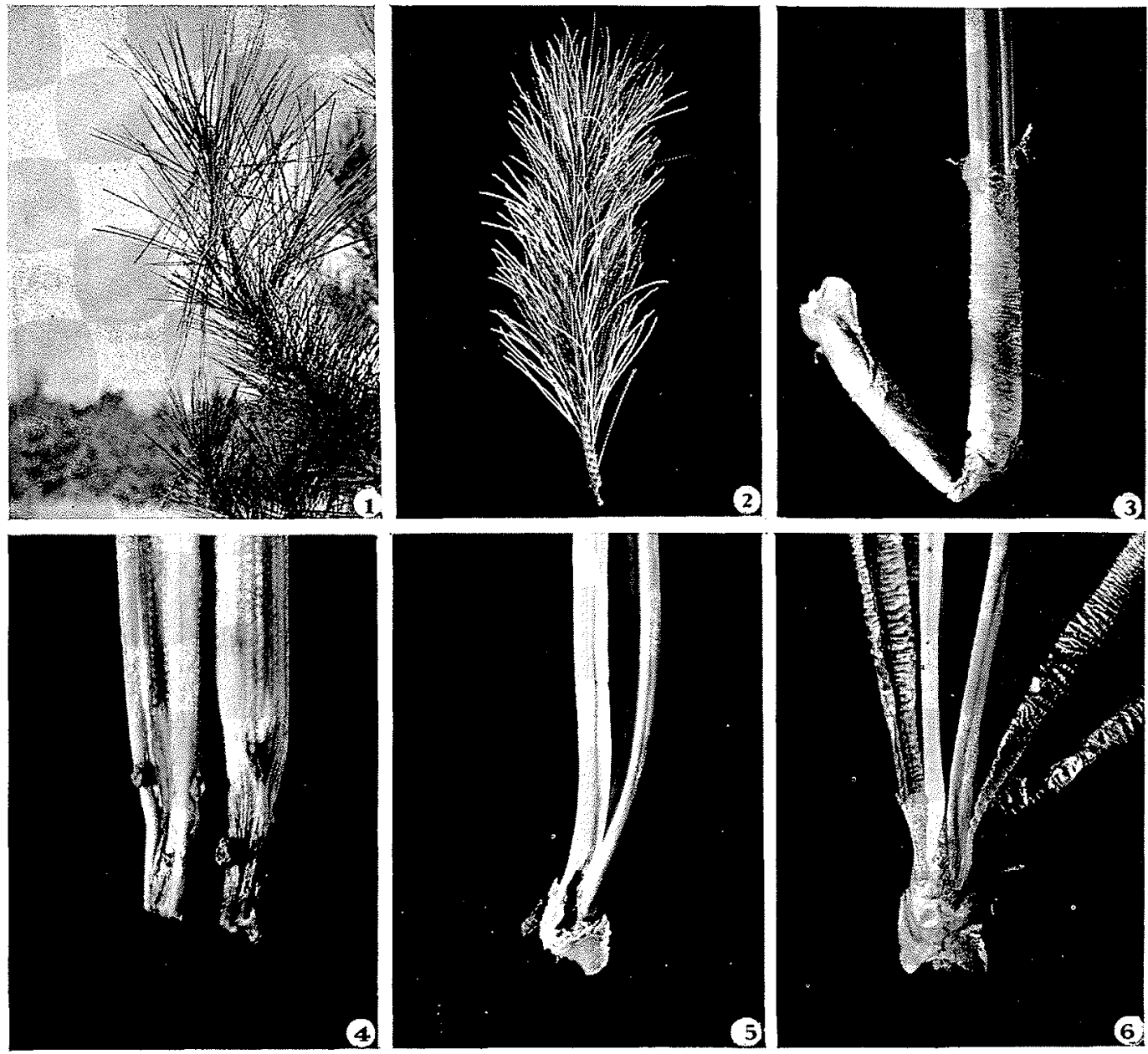

Plate No. 1

Irig. 1. Bough of red pine (Pinus resinosa Ait.) with "neerle blight" ol lateral sloot of current season. (Aug. 5th).

rig. 2. Terminal lateral shoot of red pine showing "late fall browning:" Seventy-five pel cent, of foliage alfected. (Oct. 20th).

Fig. 3. Abscissed short shoot showing crooked characteristic of "needle blight," ( $\mathrm{x}-3.5$ )

Fig. 4. Blighted neerles withdrawn from sheath of scales, showing erumpent sclerotia and anostiolate pycniclia of Pullularia pullulans. These needles overwintered on the ground. (Apr. 15th). (x-7)

Fig. 5. "Late fall browning" of red pine. Short shoot with scales dissected away to show the basal cavity caused by the larva of a gall midge. ( $\mathrm{x}-2.8)$

Fig. 6. Larvae of a gall midge at base of needles, inside the sheath of scales. Two are shown. As a rule only one is found in each short shoot. $(x-2.8)$ 
If, from a hooked fascicle, the needles are withdrawn, it will be found that a zone near the base of each has become necrotic and resinous. This lesion which is at the curvature of the hook, may be almost a centimetre long, and its occurrence actually accounts for the curvature and gradual death of the whole needle. From these lesions the fungus Pullularia pullulans (de Bary) Berkhout (= Dematium pullulans de Bary) may be regularly isolated and such infection, following initial injury by the ovipositing of a gall midge, is believed to be the cause of the condition found. In late summer and fall, and particularly the following spring, sclerotia of the fungus appear superficially on the needle bases within the sheath.

In the case of late fall browning which, it will be recalled, occurs a month or so later than blight, the needle pairs, although dead and brown, retain their normal position (habit) on the shoot and do not exhibit the crooking characteristic of the earlier phase. In withdrawing the needles from their sheaths, however, certain diagnostic signs are evident. If fortunate, one may discover a small reddish grub, the gall midge larva, lying within the sheath, in a cavity at the very base of the needles. Perhaps the larva has moved from its original position, towards the distal end of the sheath, or it may have cmerged in which case its former presence is indicated by the characteristic basal cavity which seems to be caused by pressure of the insect's body.

Thus both the "needle blight" and "late fall browning" of red pine described herein have a common origin in the ovipositing of a gall midge. If the wounded needle bases become infected with Pullularia pullulans before they are thoroughly matured, typical needle blight develops. If, on the other hand, they remain uninfected or escape infection until they are hard enough to resist crooking, the gall midge larvae mature and in so doing induce fall browning which seems to be due to injury caused by the grub alone. 